International Journal of English Literature and Social Sciences
Vol-6, Issue-2; Mar-Apr, 2021
Journal Home Page Available: https://ijels.com/
Journal DOI: $10.22161 /$ ijels

\title{
Motivational Role of Teaching English Literature in Language Learning
}

\author{
Dr. Vandana Sharma
}

Assistant Professor, Department of English Language, Jazan University, Kingdom of Saudi Arabia

Received: 09 Dec 2020; Received in revised form: 14 Feb 2021; Accepted: 02 Mar 2021; Available online: 27 Mar 2021 C2021 The Author(s). Published by Infogain Publication. This is an open access article under the CC BY license (https://creativecommons.org/licenses/by/4.0/).

\begin{abstract}
This research paper investigates the importance of motivation in the English teaching-learning process for non-native English-speaking students with a special focus on English literature. To reach a conclusion, the researcher studied the psychological aspects of students/ learners and various methods being adopted for teaching to maintain the learners' interest. Motivation has a direct impact on the behavior of anyone. According to Rayan and Deci, "to be motivated means to be moved or do something." The researcher has analyzed various motivational psychology theories to determine how a teacher can understand his students' mental status and solve their issues related to learning through multiple methods of motivation. This research paper is an in-depth study of the role of using motivational theories of Educational Psychology for teaching English literature \& language.
\end{abstract}

Keywords — language, literature, teaching-learning, motivation, motivational psychology.

\section{INTRODUCTION}

The roots of Psychology could be traced back to Philosophy and Science. When Psychotherapists started using scientific methods to study the mind in the nineteenth century, Psychology became an independent scientific discipline. The word Psychology is derived from Greek roots Psyche and logia, where psyche means 'soul' and logia means 'study of'.

Some psychologist called psychology a branch of education, as James Mill implied in the early nineteenth century. However, some psychologists disagree with those who were defending the relationship between education and psychology. The question arises how Psychology can be effectively applied to a practical field, like education. Educational Psychology enhances teachers' vision to understand their students' mental status, which helps to evaluate them to measure their intellect. Therefore, the undergraduate, graduate and postgraduate courses for those interested in taking the job in education have a compulsory subject known as Educational Psychology.

This research paper is an attempt to show the catalytic role of English literature as a motivational tool while teaching the English language Motivation is an essential tool in creating interest in anything. Without interest, no one can focus on and accomplish the task to reach the goal. Being an academician for the past more than twenty-eight years, the present research has dealt with several teachinglearning issues. If the students lack interest, the lecture gets boring, which further produces a dominos effect. The teacher also starts losing interest in teaching, and the whole process of teaching and learning gets frustrating. Therefore, motivation is one of the most prominent aspects of education and has shown a remarkable effect on the learning process.

\section{METHODOLOGY}

Educational Psychology is the scientific study of human learning. The study of an affective-cognitive theory will allow the researchers to understand individual differences in behavior, personality, intellect, and self-concept. Educational psychology heavily relies on testing, measurement, assessment, evaluation, and training processes. This can involve studying the instructional process within the classroom setting. 
The concept of motivational psychology has been implemented in detail to write this research paper. The present researcher studied the work of great psychoanalysts like Freud and Jung for this purpose. After doing psychoanalysis on the subjects under study and the theory of behaviorism, their ideas have been used to prove the importance of motivation in the teaching and learning process. To reach a conclusion, the researcher has also used her personal experience in the field of teaching at the university level. Various theories of educational psychology have been used to write this paper.

\section{Discussion:}

First of all, the author of this article would like to explain some basic concepts related to the topic to the readers.

\section{Language:}

Language is a human system of communication that uses arbitrary signals, such as voice sounds, gestures, or written symbols. "Language is a purely human and noninstinctive method of communicating ideas, emotions and desires by means of voluntarily produced symbols." (Edward Sapir, Language: An Introduction to the Study of Speech. Harcourt, Brace and Company, 1921). "A language is a system of arbitrary vocal symbols by means of which a social group cooperates." (B. Bloch and G. Trager, Outline of Linguistic Analysis. Waverly Press, 1942).

Roman Jakobson defined six functions of language (or communication functions), according to which an effective act of verbal communication can be described. Each of the functions has an associated factor. For this work, Jakobson was influenced by Karl Buhler's Organon-Model, to which he added the poetic, phatic and meta lingual functions.

The referential function corresponds to the factor of context and describes a situation, object or mental state. The descriptive statement of the referential function can consist of both definite descriptions and deictic words e.g. "The autumn leaves have all fallen now." The expressive or affective function can be best explained by interjections and other sound changes that a do not alter the denotative meaning of an utterance but do add information about the speaker's internal state e.g., "Wow! That's unbelievable!" The cognitive function engages the addressee directly which can be best illustrated by vocatives and imperatives like... "Harry! Where are you going?" or "Hi! How are you?" The poetic function of a language focuses on the message for its own sake and is the operative function in poetry as well as slogans. One more is the phatic function; it can be observed in greetings particularly with strangers e.g., "Hey you!"
There are three aspects of evolutionary psychology of a language: language as an adaptation, language as a cognitive byproduct, and exaptation. Language as an adaptation: Steven Pinker and Paul Bloom argue that the human language faculty is a complex biological adaptation that evolved by natural selection for communication in using socially interdependent lifestyle. Although, Pinker agrees with Noam Chomsky (a linguist) in arguing the fact that children can learn any human language with no explicit instruction, suggests that language including most of grammar is basically innate and that it is only needs to be activated by interaction, yet he argues that the organic nature of language strongly suggests that it has an adaptational origin. Language as a cognitive byproduct/ Spandrel: As a linguist Noam Chomsky emphasized on the infinite capacity of speech and speaking. His views that the cognitive abilities have evolved as an essential part of human language for communication. This view was supported by Steven Pinker in 1990, when he supported Chomsky's view of innate grammatical rules of language instinct". But he gave his own opinion that the selection on their linguistic function could support the conditional nature of the rules. In "The Pleasure of Pluralism", Gould argues that most universal cognitive functions are probably spandrels:

"The human brain is the most complicated device for reasoning and calculating, and for expressing emotion, ever evolved on earth. Natural selection made the human brain big, but most of our mental properties and potentials may be spandrels that is, nonadaptive side consequences of building a device with such structural complexity. If I put a small computer (no match for a brain) in my factory, my adaptive reasons for so doing (to keep accounts and issue paychecks) represent a tiny subset of what the computer, by virtue of inherent structure, can do (factor-analyze my data on land snails, beat or tie anyone perpetually in tictac-toe). In pure numbers, the spandrels overwhelm the adaptations."

Exaptation: Gould (1991) provided two related definitions of exaptations. First, an exaptation is... "a feature, now useful to an organism, that did not arise as an adaptation for its present role but was subsequently co-opted for its current function" (p. 43). Second, exaptations are... "features that now enhance fitness, but were not built by natural selection for their current role" (p. 47). On the basis of these related definitions, a mechanism must have a function and must enhance the fitness of its bearer to qualify as an exaptation."

All the above discussed points lead to the adaptation with natural selection as the species evolves as suggested by Charles Darwin in his book titled "On the Origin of 
Species by Means of Natural Selection" Darwin.18591958.

\section{Motivational Psychology:}

In all kinds of educational field, motivation is considered as one of the most efficacious factors. Crookes and Schmidt (1991) described motivation as the learner's orientation in relation to the goal of learning a second language. According to Steers and Porter (1991), "motivation can be characterized as follows: needs or expectations, behavior, goals and some form of feedback." Rayan and Deci state, "to be motivated means to be moved to do something." (2000a, p.54). Dörnyei explains that human behavior has two dimensions - direction and magnitude (intensity). Motivation is related to these concepts, and "it is responsible for the choice of a particular action and the effort expanded on it and the persistence with it." (Dörnyei, 2001a:7)

Gardener proposes that motivation, along with the language aptitude is the main element which determines success in learning another language in the classroom setting.

As per (William and Burden, 1997, p.111) "Interest, curiosity, or a desire to achieve" which is true to the teaching learning process and the role of motivation in it. By motivating the teacher can evoke the interest of students and mention their interest to achieve the goal.

According to Santrock an educational psychologist, "the art of teaching is the awakening of the curiosity of young minds. Arousing pupils' interests is one of the sole factors in the teaching earning process." (2001; 401-402)

Motivation can be best explained by the Attribution theory which mainly states how individuals interpret events and how this relates to their thinking and behavior. Weiner and colleagues (e.g., Jones et al, 1972; Weiner, 1974, 1986) developed a theoretical framework that has become a major research paradigm of social psychology. Attribution theory assumes that people try to determine why people do what they do, i.e., attribute causes to behavior. A person seeking to understand why another person did something may attribute one or more causes to that behavior. A three-stage process underlies an attribution: (1) the person must perceive or observe the behavior, (2) then the person must believe that the behavior was intentionally performed, and (3) then the person must determine if they believe the other person was forced to perform the behavior (in which case the cause is attributed to the situation) or not (in which case the cause is attributed to the other person).
The goal of learning cannot be achieved without having attention. If a student has attention disorder or it the lack of interest, the teacher has to use various methods to remove that boredom. Drawing attention of the learners the teacher uses external methods while the students should have internal motivation. If external factor is any form of native English literature the learner will start creating pictures in his/her brain of that time, ways of life, manners, and the way English language was/is spoken. It will start an operational internal learning process. This gives fuel to the cognitive skill and knowledge or information achieved is a long-term memory.

According to American psychologist Abraham Maslow in 1943, humans are inherently motivated to better themselves and move toward expressing their full potential - self-actualization - by progressively encountering and satisfying several levels of need from the most fundamental, such as for food and safety, to higherorder needs for love, belonging, and self - esteem. His views regarding effect of motivation on the behavior of an individual are "...behavior is determined by several classes of determinants, of which motivation is one and environmental forces are another... that motivation is constant, never ending, fluctuating, and complex, and that it is an almost universal characteristic of practically every organismic state of affairs. (Maslow, 1954, p. 11, p. 69)

Literature helps the students to focus their attention on the teaching material which is in the form of story, poem or an article and will help them to initiate their learning ability. The teacher can use the non-verbal methods like, audio-visual aids viz. power point presentation having pictorial depiction of the story/poem, use of videos, movies, and traditional verbal method of classroom teaching. The main aim is to motivate the students and connect them to a non-native language by imbibing them into the relative literature. It will help them to learn the values of another culture and in a way develop an understanding and acceptance for a good social life in the global world.

Learning involves reception, recognition, perception, semantic encoding, storing in long - term memory and retrieving when it is needed. Here The researcher would like to give two examples to prove the importance of learning a language through literature using the later as a motivational tool. First example is the poem 'Stopping by the Woods on a Snowy Evening' by Robert Frost. This poem not only describes the geographical condition and nature's beauty but also teaches the value of duty. It gives the message of 'Work is worship'. The poet is captivated by nature's beauty while traveling through the woods but his duty towards his work is divine, so he moves ahead in favor of his duty. The poetry begins with 
the dazzling beauty of nature and ends in imparting the wisdom. It motivates the learner by creating and maintaining the interest and thereby helping in learning the language too.

Learning to speak proper English through the play Pygmalion by George Bernard Shaw is the best example to support the present paper. This play is a wonderful amalgamation of British society, their mannerism and Phonetics to teach proper spoken English. This play stimulates the students to search for the proper pronunciation of English language.

\section{CONCLUSION}

There are various effective methods of teaching and learning English as a second language. Reading, writing, listening, and speaking are the four skills that are generally being taught to non-native English speakers. The necessity to learn English as a second language becomes in the age of globalization when the main language of communication for business and trade is English. The incentive theory suggests that people are motivated to do things because of external rewards. In the situated view, motivation is seen largely as a result of socio-cultural constructs and interactions with the environment (Pintrich 680-681).

As a teacher of English literature, the researcher feels that teaching the English language by using English literature as a tool can be more enjoyable and will facilitate the students to understand not only the language but the British culture also. It will create interest amongst the students leading them towards achieving the goal. Learning the English language by using English literature as a tool can be one of the most effective methods of motivation. The students with the knowledge of English culture, customs, and lifestyle through English literature can better absorb the English language like native English speakers.

If an English language learner is learning the English language through English literature, it will help him/ her in understanding the native culture. The incentive here is if he/she goes to study abroad for further studies. The mixing in the local environment becomes easy for them. Moreover, it will help in providing an opportunity in the global job market.

The hierarchy of needs theory of Maslow suggests that these needs were universal to humans, but that they could manifest in myriad ways based on environmental conditions and an individual's history (Maslow 28-29). It also suggests that some external reward is needed for a person to do a certain task. Thus, a congenial atmosphere can be established by teaching English literature to create students' interest in language learning plays an important role.

\section{REFERENCES}

[1] Darwin, C. (1958). On the origin of species by means of natural selection. (New York: New American Library. (Original work published 1859)

[2] Dörnyei, Z. (2001a). Motivational strategies in the language classroom. UK: Cambridge University Press.

[3] Gardner, R. ( 2001b) Language learning motivation: The student, the teacher and the researcher. Key-note address to the Texas Foreign Language Education Conference, University of Texas, Austin.

[4] Gould, S. J. \& Lewontin, R. C. (1979). The spandrels of San Marco and the Panglossian paradigm: A critique of the adaptationist programme. Proceedings of the Royal Society of London B, 205, 581-598.

[5] Maslow, Abraham H. Motivation and Personality. 3rd Edition. New York: Longman, 1987.

[6] Pintrich, Paul R. "A Motivational Science Perspective on the Role of Student Motivation." Journal of Educational Psychology 95.4 (2003): 667-686.

[7] Deci, E. L., \& Ryan, R. M. (1985). Intrinsic motivation and self-determination in human behavior. New York: Plenum.

[8] Orr, David. The Road Not Taken: Finding America in the Poem Everyone Loves and Almost Everyone Gets Wrong. Penguin Books, 2015.

[9] Shaw, George Bernard. Pygmalion. Null, CreateSpace Independent Publishing Platform, 2018.

[10] Steers, R.M., and Porter, L.W. (1991). Motivation and work behavior. New York: McGraw-Hill.Inc. Lincoln.

[11] Santrock J.W. (2001), Educational Psychology, $1^{\text {st }}$ Ed. McGrew-Hill Compnies.inc.

[12] Weiner, B. (1974). Achievement motivation and attribution theory. Morristown, N.J.: General Learning Press.

[13] Weiner, B. (1980). Human Motivation. NY: Holt, Rinehart \& Winston.

[14] Weiner, B. (1986). An attributional theory of motivation and emotion. New York: Springer-Verlag.

[15] Williams, M., Burden, R (1997) Psychology for Language Teachers. Cambridge University Press. 